\title{
Modeling and Link Performance Analysis of Busbar Distribution Systems for Narrowband PLC
}

\author{
Zeynep HASIRCI, Ismail Hakki CAVDAR, Mehmet OZTURK \\ Dept. of Electrical and Electronics Engineering, Karadeniz Technical University, 61080, Trabzon, Turkey \\ \{zhasirci, cavdar, mehmetozturk\}@ktu.edu.tr \\ Submitted October 17, 2016 / Accepted December 27, 2016
}

\begin{abstract}
Busbar distribution system is used as a modular infrastructure to carry electrical energy in low voltage grid. Due to the widespread usage in industrial areas, the power line communication possibilities should be investigated in terms of smart grid concept. This paper addresses modeling of the busbar distribution system as a transmission line and gives some suggestions on the link performance for narrowband power line communication for the first time in literature. Firstly, S-parameters of different current level busbars were measured up to $500 \mathrm{kHz}$ for all possible two-port signal paths. The utilization of the frequency-dependent RLCG(f) model was proposed to extract transmission line characteristics to eliminate the unwanted measurement effects. Particle swarm algorithm was used to optimize the model parameters with a good agreement between measured and simulated S-parameters. Additionally, link performance of busbar distribution system as a power line communication channel at $3 \mathrm{kHz}-148.5 \mathrm{kHz}$ band was examined for frequency shift keying and phase shift keying modulations under different network configurations such as varying busbar type, the line length between transmitter and receiver, branch number, and terminating load impedance. Obtained results were presented as bit-error-rate vs. signal-to-noise ratio graphs.
\end{abstract}

\section{Keywords}

Bit-error-rate, busbar, channel capacity, channel modeling, M2M, narrow band, parameter optimization, power line communication, smart grid, S-parameters

\section{Introduction}

Creating alternative energy sources and increasing only production, may not be sufficient to ensure the production-consumption balance. What really matters is using energy effectively and efficiently. Smart grid disperses control of the network infrastructure. It ensures transfer and monitoring of data with a protection of various technologies. Power line communication (PLC) is one of the most powerful communication alternatives for smart grid applications that use existing grid infrastructure as the communication medium. Low voltage (LV) network is more complex than the medium/high voltage grid due to the necessity of multi-point communication network. Due to many advantages, busbar is an electrical distribution system element which has a modular structure that carries electrical energy in the buildings. They are used mostly in industrial areas which have high power consumption. Starting from the fact that solution to some problems monitoring energy from the point of production to consumption, loss-efficiency analysis, machine to machine communication (M2M) - should be more significant in the industrial field, busbars emerge as mediums that should be examined in terms of smart grids.

PLC studies on cables in the literature do not provide a complete and accurate identification for busbars mainly due to the electrical installation differences. The subject of this study has emerged from the importance of this issue in terms of inadequate scientific work conducted on. It is necessary to know the characteristics of the busbars for providing PLC communication. Accurate transmission line models are required for accurate simulation of signal paths implemented in communication systems. Such transmission line models are typically given in per-unit-length (p.u.1.) parameters (RLGC parameters) to derive the echo transfer function of the power line [1]. Whereas lossy transmission line models may equally be described in terms of the characteristic impedance $\left(Z_{\mathrm{c}}\right)$ and propagation constant $(\gamma)$, designers are generally focused on RLGC parameters. Judging from here, busbar system can also be described as a transmission line [2], [3] and can be represented with RLGC parameters as the other power cables. In the literature, there are many studies about power cables and extraction of the p.u.l. parameters. Many of these studies are based on S-parameters measurements [1], [4-8]. Besides, others are based on time-domain measurements [9-11]. Some methods support the calculation of the RLCG parameters from $Z_{\mathrm{c}}$ and $\gamma[1,4,12]$. Almost other methods estimate $Z_{\mathrm{c}}$ from $\gamma$ extracted from measurements by some assumptions [13-17]. Additionally, line parameters extraction is made with some optimization algorithms such as genetic algorithm etc. [18-20].

There is a few study about busbars for PLC. [2] reports scattering parameters of the copper conductor series 
1000 A busbar system by an EM analysis simulation tool for CENELEC (European Committee for Electrotechnical Standardization), FCC (Federal Communications Commission) and Broadband, [3] presented propagation characteristics of different current levels copper conductor series busbar systems in 1-50 MHz. [2] and [3] are simulation based studies for copper conductor series busbar system and need experimental validation. Then, more preferable type aluminum conductor series busbar system (630 A) are modeled by Sonnet Suites 13.52 and results are validated with measured S-parameters [21]. [22] presented a parameter extraction approach for $630 \mathrm{~A}$ busbar.

In this study, S-parameters of different current level busbar distribution systems (630 A, 1250 A, 2000 A) were measured with a Vector Network Analyzer (VNA) up to $500 \mathrm{kHz}$ for all possible signal paths. RLCG $(f)$ modeling procedure was used to estimate p.u.l. parameters. After particle swarm optimization algorithm (PSO), the measured and simulated S-parameters (from the model) show a good agreement. With the utilization of the chain-scattering matrix method, different combinations of single-branch networks were simulated for N-branch busbar distribution network. After that, the effects of terminating load impedance, busbar line length, and branch number on the system performance in terms of the bit-error-rate (BER) were calculated for FSK and PSK modulations. BER vs. signalto-noise ratio (SNR) graphics were presented for different busbar network configurations.

\section{Modeling of Busbar}

\subsection{Measurements and Estimation of Model Parameters}

Aluminum busbars have more widespread usage than copper ones due to their low cost. Thus, in this study, aluminum busbars which have $630 \mathrm{~A}, 1250 \mathrm{~A}$, and $2000 \mathrm{~A}$ current levels were used for measurements and modeling.

Different current levels change the physical characteristics of the busbar system such as the cross-sectional area of the conductor. Physical characteristics of used busbar systems for different current levels at $20^{\circ} \mathrm{C}$ are listed in Tab. 1 and detailed information can be found in [23].

As it is mentioned before, busbar system can also be described as a transmission line [2, 3, 21, 22] and can be represented with $Z_{\mathrm{c}}$ and $\gamma$ as other power cables to find the

\begin{tabular}{|c|c|c|c|c|c|}
\hline $\begin{array}{c}\text { Current } \\
\text { levels } \\
\text { [A] }\end{array}$ & $\begin{array}{c}\text { Resistance } \\
R[\mathrm{~m} \Omega / \mathrm{m}]\end{array}$ & $\begin{array}{c}\text { Reactance } \\
X[\mathrm{~m} \Omega / \mathrm{m}]\end{array}$ & $\begin{array}{c}\text { Impedance } \\
Z[\mathrm{~m} \Omega / \mathrm{m}]\end{array}$ & $\begin{array}{c}\text { Weight } \\
{[\mathrm{kg} / \mathrm{m}]}\end{array}$ & $\begin{array}{c}\text { Conductor } \\
\text { size } \\
{[\mathrm{mm} \times \mathrm{mm}]}\end{array}$ \\
\hline 630 & 0.121 & 0.027 & 0.124 & 7.9 & $6 \times 40$ \\
\hline 1250 & 0.044 & 0.013 & 0.046 & 13.9 & $6 \times 110$ \\
\hline 2000 & 0.026 & 0.008 & 0.027 & 21.7 & $6 \times 200$ \\
\hline
\end{tabular}

Tab. 1. Physical characteristics of used busbar systems for different current levels at $50 \mathrm{~Hz}$ [23]. transfer function of the communication channel. It is a three-phase system (L1, L2, L3) with a neutral (N) and it can be analyzed as six different two-port networks for L1-N, L2-N, L3-N, L2-L1, L3-L1, and L3-L2 port connections (signal paths), separately. It is commonly known that a two-port device can be described by some parameter sets such as impedance, admittance, hybrid and voltage/ current transmission matrices at each of the two ports. For these type measurements, ideal short/open circuit terminations are required. However, frequency dependence of these terminations can have caused measurement issues. Thus, traveling waves as variables, S-parameters, can be a good alternative to overcome extra measurement faults. S-parameters are defined with respect to traveling waves, unlike terminal voltages and currents and can be measured on a device located at some distance from the instrument [24]. These measurements are carried out by terminating one or the other port with normalizing impedance $Z_{0}$ (generally $50 \Omega$ ) [1], [25]. Two-port S-parameter measurements are made via VNA, Agilent Technologies N9913A Field Fox RF Analyzer. Measurement setup is shown in Fig. 1. Two 1.5 m length M17/75-RG214 type coaxial cables with $50 \Omega$ characteristic impedance are attached to the ports for the connection between VNA and DUT (unit length-3 m busbar) to measure the S-parameters. Two port calibration is made to eliminate the extra connection effects on measurements. However, calibration does not guarantee to eliminate the busbar S-measurement faults, the preferred method for parameter extraction plays an important role in eliminating these unwanted effects. These experimental studies are made without extra load connection to find the transmission line parameters.

S-parameters represent the relationship between normalized incident $\left(a_{1}, a_{2}\right)$ and reflected $\left(b_{1}, b_{2}\right)$ voltage waves as shown in (1).

$$
\left[\begin{array}{l}
b_{1} \\
b_{2}
\end{array}\right]=\left[\begin{array}{ll}
S_{11} & S_{12} \\
S_{21} & S_{22}
\end{array}\right]\left[\begin{array}{l}
a_{1} \\
a_{2}
\end{array}\right] .
$$
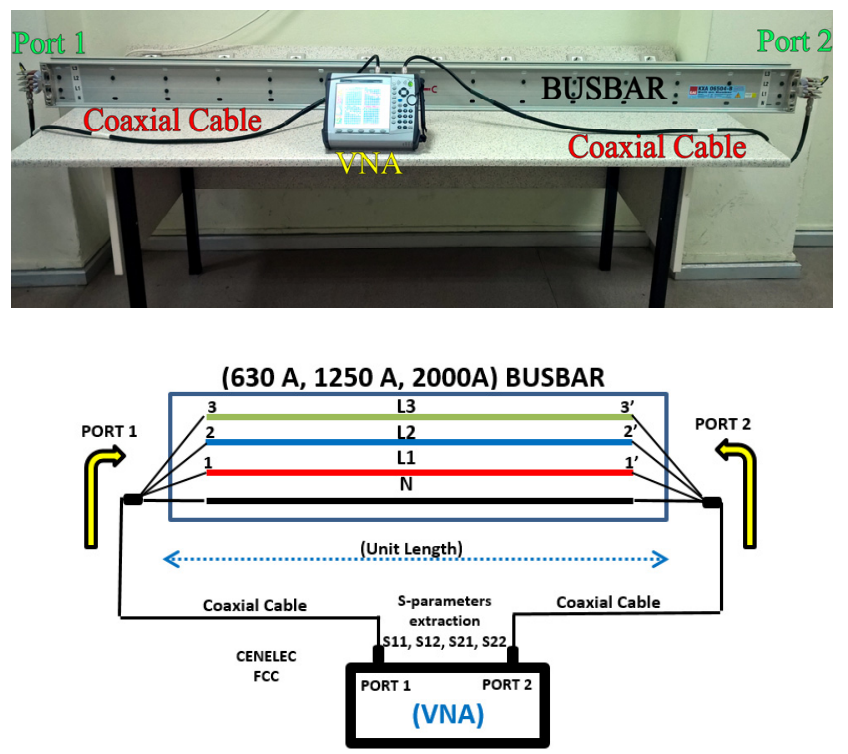

Fig. 1. Measurement setup for S-parameters. 
A network that consists entirely of linear passive components, such as transmission lines, is reciprocal. Thus, the full S-parameters matrix of the reciprocal circuit must be symmetric. That means $S_{11}=S_{22}$ (symmetric) and $S_{21}=S_{12}$ (reciprocity).

Incident and reflected voltage waves are also used to define scattering transfer parameters (T-parameters) as well S-parameters. However, T-parameters represent the relation between the waves at port 1 to the waves at port 2 as given in (2).

$$
\left[\begin{array}{l}
a_{1} \\
b_{1}
\end{array}\right]=\left[\begin{array}{ll}
T_{11} & T_{12} \\
T_{21} & T_{22}
\end{array}\right]\left[\begin{array}{l}
b_{2} \\
a_{2}
\end{array}\right] .
$$

The direct measurement of T-parameters is not as easy as S-parameters. Thus, S-parameters were measured and used for busbar modeling. Then, due to the ease of calculating cascaded networks by matrix multiplication with T-parameters, S-matrix of each single-branch network was converted to T-matrix as explained in Sec. 3 .

Necessary parameters to find the transfer function of a transmission line $\left(Z_{\mathrm{c}}\right.$ and $\left.\gamma\right)$ can be calculated as (3) and (4) if p.u.l. parameters are known.

$$
\begin{gathered}
Z_{\mathrm{c}}=\sqrt{\frac{R+\mathrm{j} \omega L}{G+\mathrm{j} \omega C}}, \\
\gamma=\alpha+\mathrm{j} \beta=\sqrt{(R+\mathrm{j} \omega L)(G+\mathrm{j} \omega C)} .
\end{gathered}
$$

There are some conventional and modified transmission line characterization methods from VNA measurements [25], [26-28]. This paper uses frequency-dependent $R L G C(f)$ model method for p.u.l. parameters extraction from measured S-parameters. The results have been more accurate and efficient in a large frequency band due to they eliminate the discontinuity caused by the hyperbolic functions [18-20], [22]. Additionally, the limitations of the conventional methods such as specific line lengths, frequencies, the number of lines, etc. will be exceeded. Estimation of p.u.l. parameters from measurements with modeling includes the minimization of an objective function which can generally be non-linear. The error between measured data and the data from the model defines the objective function. In this study, the objective function consists of mean squared errors between real (Re) and imaginary (Im) parts of only $S_{11}$ and $S_{21}$ as given in (5) due to the reciprocity. The modeling experiments using the only magnitude of $S_{21}$ gives relatively significant estimation errors on $S_{11}$. Thus, with including Re and Im parts of $S_{11}$ and $S_{21}$ parameters in the objective function, optimized unit length element of transmission line parameters will reveal the measured data more accurately.

$$
F_{\text {obj }}=\frac{1}{M} \sum_{i=1}^{M}\left\{\begin{array}{l}
\operatorname{Re}\left(S_{11}^{\mathrm{m}}\left(f_{i}\right)-S_{11}^{\mathrm{e}}\left(f_{i}\right)\right)^{2}+ \\
\operatorname{Re}\left(S_{21}^{\mathrm{m}}\left(f_{i}\right)-S_{21}^{\mathrm{e}}\left(f_{i}\right)\right)^{2}+ \\
\operatorname{Im}\left(S_{11}^{\mathrm{m}}\left(f_{i}\right)-S_{11}^{\mathrm{e}}\left(f_{i}\right)\right)^{2}+ \\
\operatorname{Im}\left(S_{21}^{\mathrm{m}}\left(f_{i}\right)-S_{21}^{\mathrm{e}}\left(f_{i}\right)\right)^{2}
\end{array}\right\}
$$

In (5), $M$ is the total number of measurement points, $S^{\mathrm{m}}\left(f_{i}\right)$ and $S^{\mathrm{e}}\left(f_{i}\right)$ correspond to measured and estimated Sparameters, respectively. PSO [29] was selected to minimize $F_{\text {obj }}$ due to its superior performance to find global minimum in case of a large parameter search range. In our previous study [17], a trial and error method was utilized. This method needs some well-selected initial values, unlike PSO which only needs parameter search bounds. Thus, in [22], trial and error procedure started at the point that is inspired from extracted parameters of a parallel plate transmission line. When modeling a different type of busbar (different current level), a different set of initial values has to be selected for optimization. With PSO, this difficulty is removed, and the algorithm is generalized in this paper.

A frequency-dependent $R L G C(f)$ model was used to extract the p.u.l. parameters of the busbar transmission line as in (6)

$$
\begin{aligned}
& R(f)=R_{1}+R_{2} \sqrt{f}, \\
& L(f)=L_{1}+R_{2} /(2 \pi \sqrt{f}), \\
& G(f)=G_{1}+G_{2} f, \\
& C(f)=C_{1}
\end{aligned}
$$

where $R_{1}, R_{2}, L_{1}, G_{1}, G_{2}$, and $C_{1}$ are constant unknowns that should be estimated. $R_{1}, R_{2}, L_{1}, G_{1}, G_{2}$, and $C_{1}$ refer to DC resistance, skin effect loss, inductance at high frequencies (generally constant), shunt current due to free electrons in an imperfect dielectric, power loss due to dielectric polarization, and geometry-related capacitance constant, respectively. For all different type busbar modeling procedures, the search range set given in Tab. 2 was used.

The conversion from RLGC parameters to S-parameters starts with calculation of $Z_{\mathrm{c}}$ and $\gamma$ with (3) and (4), respectively. Then, for a specific line length of busbar $(l=3 \mathrm{~m})$, ABCD matrix is created with known $Z_{\mathrm{c}}$ and $\gamma$ parameters as in (7)

$$
\left[\begin{array}{ll}
A & B \\
C & D
\end{array}\right]=\left[\begin{array}{cc}
Z_{c} \cosh (\gamma l) Z_{c}^{-1} & Z_{c} \sinh (\gamma l) \\
\sinh (\gamma l) Z_{c}^{-1} & \cosh (\gamma l)
\end{array}\right] .
$$

Finally, the S-parameters for busbar $S^{\mathrm{e}}$ are obtained from the ABCD matrix as in (8) [30].

$$
\begin{aligned}
& S^{\mathrm{e}}=\left[\begin{array}{ll}
S_{11}^{\mathrm{e}} & S_{12}^{\mathrm{e}} \\
S_{21}^{\mathrm{e}} & S_{22}^{\mathrm{e}}
\end{array}\right]= \\
& {\left[\begin{array}{cc}
\frac{A Z_{0}+B-C Z_{0}{ }^{2}-D Z_{0}}{\mathrm{X}} & \frac{2(A D-B C) Z_{0}}{\mathrm{X}} \\
\frac{2 Z_{0}}{\mathrm{X}} & \frac{-A Z_{0}+B-C Z_{0}{ }^{2}+D Z_{0}}{\mathrm{X}}
\end{array}\right]} \\
& X=A Z_{0}+B+C Z_{0}{ }^{2}+D Z_{0} .
\end{aligned}
$$

The overall parameter estimation process with PSO is given as a flowchart in Fig. 2. 


\begin{tabular}{|c|c|c|c|c|c|}
\hline $\begin{array}{c}\boldsymbol{R}_{\mathbf{1}} \\
{[\Omega / \mathrm{m}]}\end{array}$ & $\begin{array}{c}\boldsymbol{R}_{\mathbf{2}} \\
{[\Omega /(\mathrm{m} \sqrt{\mathrm{Hz}}]}\end{array}$ & $\begin{array}{c}\boldsymbol{L}_{\mathbf{1}} \\
{[\mathrm{H} / \mathrm{m}]}\end{array}$ & $\begin{array}{c}\boldsymbol{G}_{\mathbf{1}} \\
{[\mathrm{S} / \mathrm{m}]}\end{array}$ & $\begin{array}{c}\boldsymbol{G}_{\mathbf{2}} \\
{[\Omega /(\mathrm{mHz}]}\end{array}$ & $\begin{array}{c}\boldsymbol{C}_{\mathbf{1}} \\
{[\mathrm{F} / \mathrm{m}]}\end{array}$ \\
\hline $0 \sim 10$ & $0 \sim 1$ & $0 \sim 10^{-5}$ & $0 \sim 1$ & $10^{-11} \sim 10^{-8}$ & $10^{-11} \sim 10^{-8}$ \\
\hline
\end{tabular}

Tab. 2. Lower and upper bounds of parameters used in PSO.

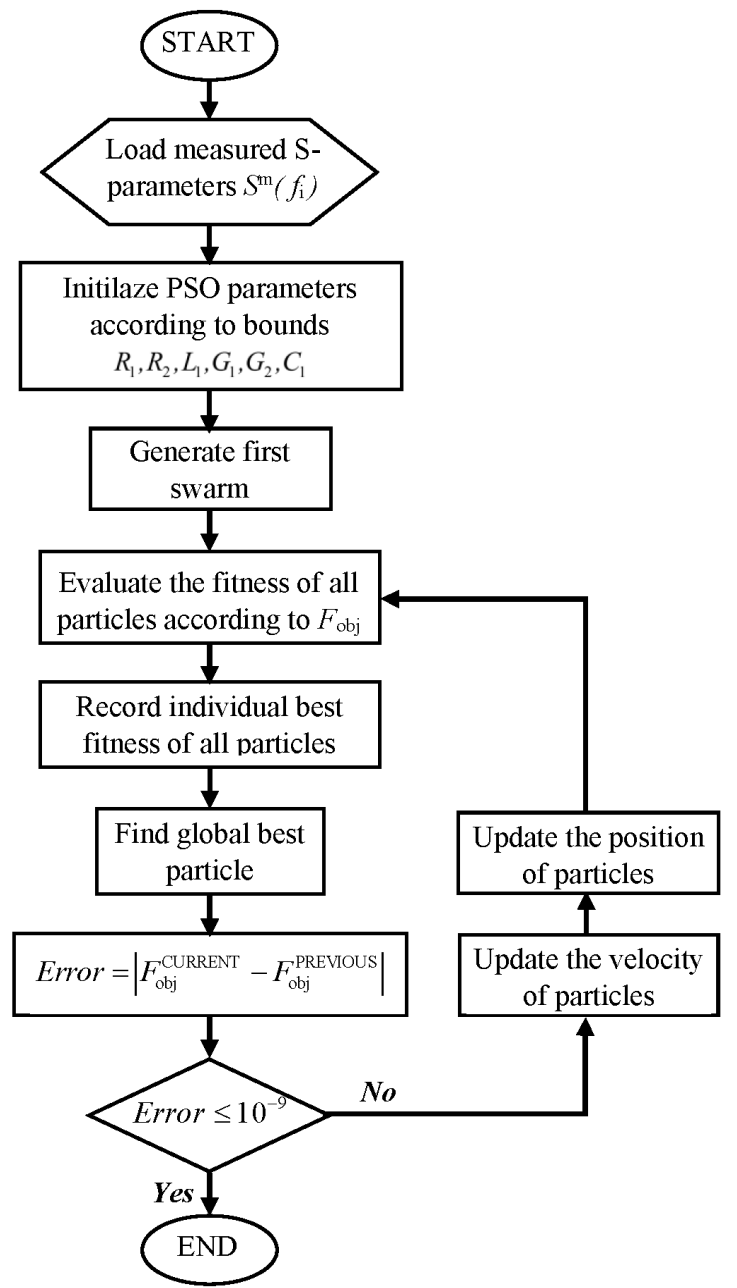

Fig. 2. Optimization process flowchart of the model parameter extraction.

\subsection{Modeling Results}

In this study, all of the signal paths were modeled for each current level busbar and the results were analyzed. As there are 18 different estimation results, it is not feasible to draw all of the combinations in this paper. Thus, a comparison of measured and simulated S-parameters for only some phase to neutral (L1-N, L2-L1, L3-N) and phase to phase (L2-L1 L3-L1, L3-L2) signal paths of $630 \mathrm{~A}$, $1250 \mathrm{~A}$, and $2000 \mathrm{~A}$ current level busbars are given in Figs. 3, 4, and 5, respectively. As the objective function uses measured S-parameters, visual presentations of results are given as a qualitative analysis. On the other hand, since the voltage transfer function of a two-port network is $S_{21}$, the goodness of fit value was calculated via amplitude and phase of $S_{21}$. The R-square value [31] was used as quantitative error measure. The averaged R-square values are 0.93 and 0.98 for amplitude and phase of $S_{21}$, respectively.

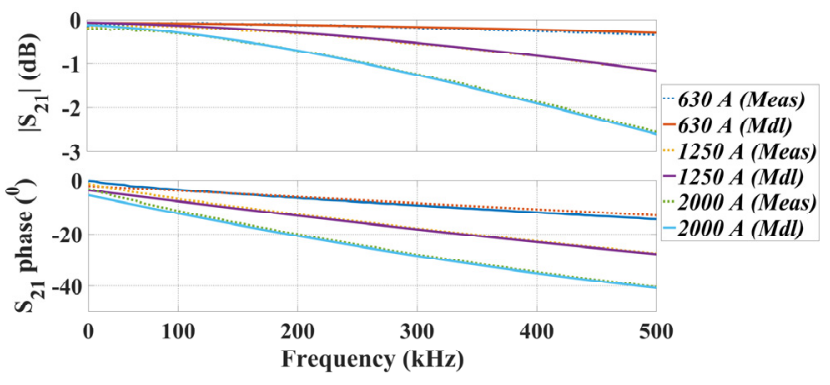

Fig. 3. Measured (Meas) and Estimated $(M d l) S_{21}$ parameters for L1-N signal path (3 m).

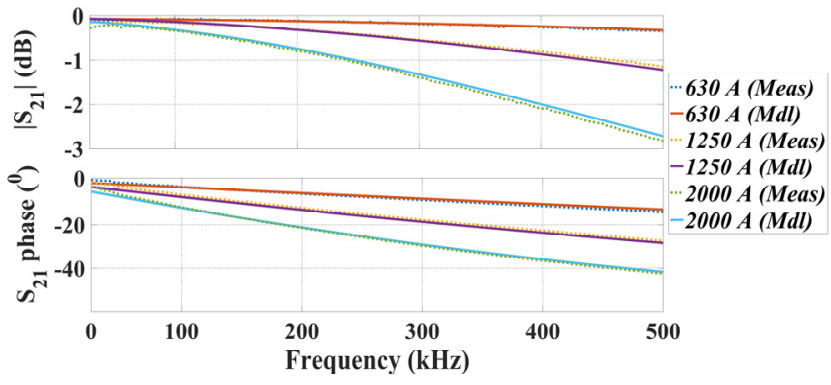

Fig. 4. Measured (Meas) and Estimated $(M d l) S_{21}$ parameters for L2-L1 signal path (3 m).

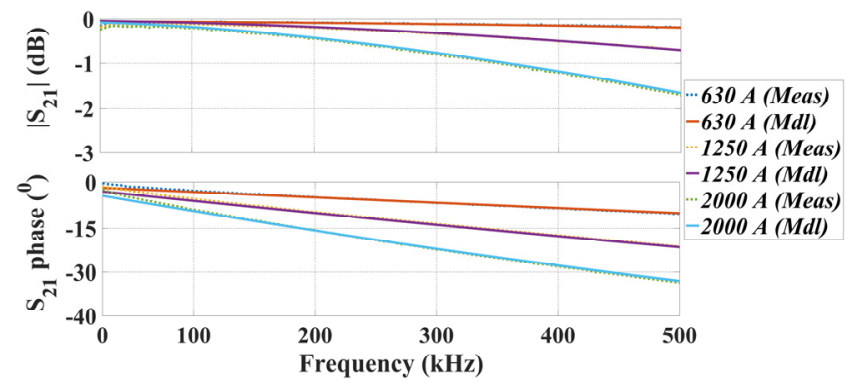

Fig. 5. Measured (Meas) and Estimated $(M d l) S_{21}$ parameters for L3-N signal path (3 m).

Because the R-square value of 1 means an exact match, the obtained error values show that the model results can be considered as a very close estimation.

Calculated frequency-dependent RLGC values are presented in Figs. 6, 7 and 8 for different current level busbars for some signal paths. When the figures are examined, it is easily seen that resistance and inductance are decreased with the increasing cross-section area as expected for all signal paths. Additionally, conductance and capacitance are increased.

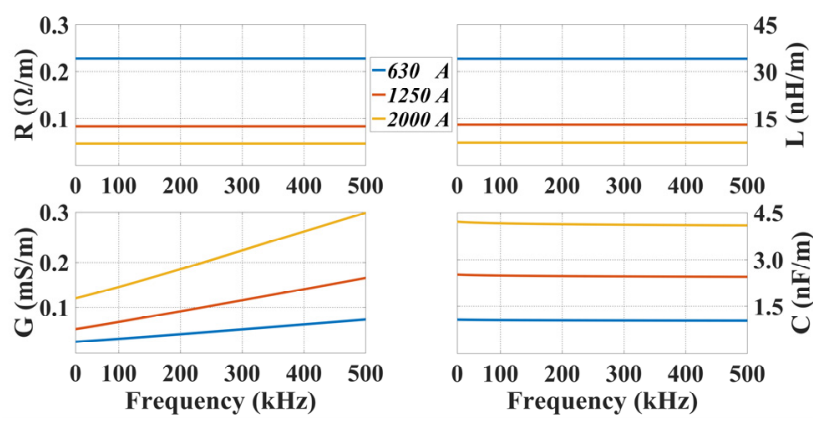

Fig. 6. Estimated RLGC parameters of different current level busbars from measured S-parameters for L1-N signal path. 

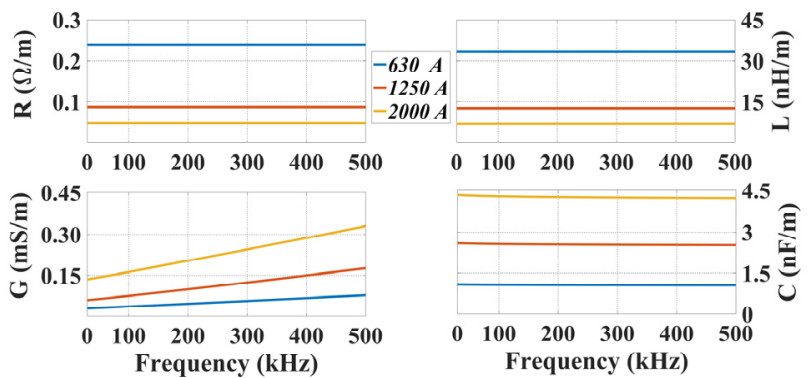

Fig. 7. Estimated RLGC parameters of different current level busbars from measured S-parameters for L2-L1 signal path.
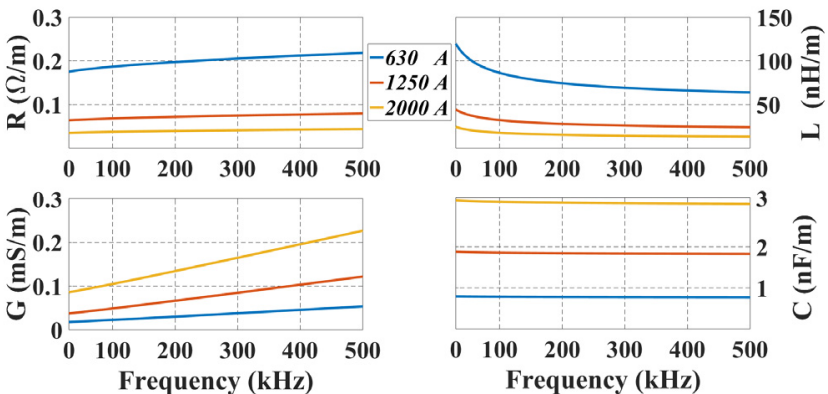

Fig. 8. Estimated RLGC parameters of different current level busbars from measured S-parameters for L3-N signal path.

In this study, busbar was considered and analyzed as a two-port network. So, there are six different two-port signal paths in total. Each signal path has different characteristics, such as differences in spacing between conductors, and can be thought of as a different transmission line. In this sense, it is expected for the obtained RLGC values to be different. Additionally, L1-N and L2-L1 signal paths have physically similar conditions (such as inter-conductor distances and insulating layer thickness). For this reason, similar RLGC values are estimated, as can be seen from Figs. 6 and 7. On the other hand, L3-N has some differences such as distance between conductors and an increased insulation thickness. This is the main reason for the differences between the estimated RLGC values.

\section{Bit-Error-Rate Performance Analysis}

Due to the fact that busbar distribution system has been originally designed for electricity transfer, it has a hostile environment for data communication. Noise is one of the primary problems for PLC systems as well as attenuation. Electronic devices which are connected to the power network are the typical noise sources. The noise characteristics are generally cyclostationary both in time and frequency domain and added to additive white Gaussian noise (AWGN) [32], [33].

The averaged power spectral density (PSD) for the typical colored background noise in narrowband PLC can be seen in Fig. 9 [34]. In this study, we used an assumption

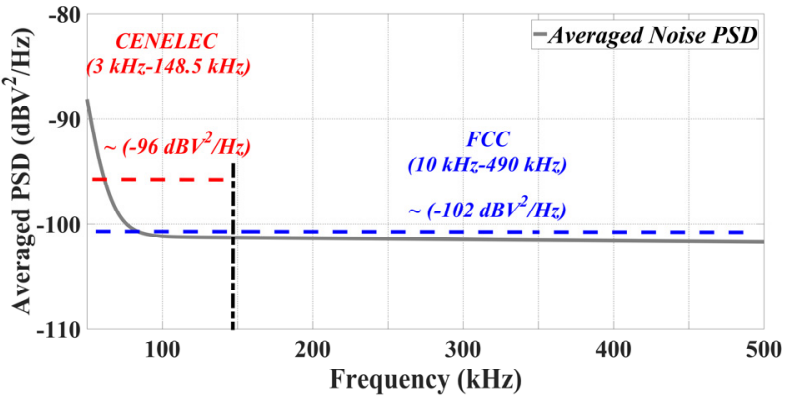

Fig. 9. Averaged PSD of background noise [27].

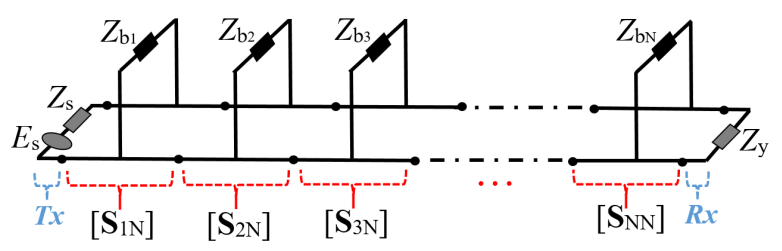

Fig. 10. An example of a busbar distribution network.

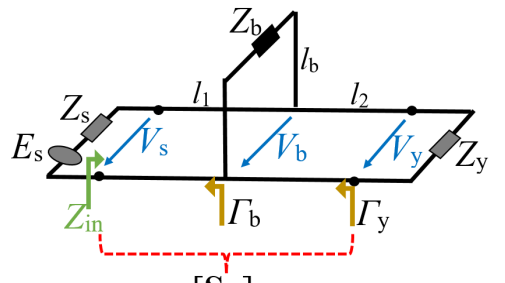

$\left[\mathbf{S}_{\mathrm{N}}\right]$

Fig. 11. Representation of a single-branch network.

that the noise PSD is constant as approximately $96 \mathrm{dBV}^{2} / \mathrm{Hz}$ for the theoretical BER calculations at CENELEC band according to Fig. 9.

The attenuation is another important parameter for the PLC and it is directly related to the channel transfer function. When $Z_{\mathrm{c}}$ and $\gamma$ are known, the transfer function of the PLC channel can be determined. In this study, bottom-up frequency-domain channel modeling approach was preferred. $Z_{\mathrm{c}}$ and $\gamma$ parameters were calculated from (2) and (3) for all busbar types and each signal paths with the help of estimated RLGC parameters. Basically, the busbar PLC channel can be defined as separated N-cascaded singlebranch networks [35] as shown in Fig. 10.

Firstly, the S-matrix of each single-branch network as shown in Fig. 11 was found with the transmission line theory. Then, the chain-scattering matrix method was used to determine the whole busbar PLC network with the different combinations of single-branch networks. The $S_{21}$ term of the scattering matrix of the whole PLC network gives the desired transfer function [30]. When the configuration of the busbar PLC network is changed, the transfer function of the entire network is affected. The configuration of network changes with busbar type, signal paths, busbar line length between the transmitter $(T x)$ and the receiver $(R x)$, branch number, branch length and connected load impedance.

In Fig. $11, Z_{\mathrm{s}}, Z_{\mathrm{y}}$, and $Z_{\mathrm{b}}$ are source impedance (50 $\Omega$ ), load impedance $(50 \Omega)$, and branch load impedance, re- 
spectively. $Z_{\text {in }}$ corresponds to the input impedance of the whole single-branch network. $\Gamma_{\mathrm{y}}$ and $\Gamma_{\mathrm{b}}$ refer to the reflection coefficients from the load and from the branch tap, respectively. $l$ is the line lengths in $\mathrm{m}$ for the relevant part of the network. $S_{11}$ and $S_{21}$ parameters of the single-branch network can be calculated with (9) [36]

$$
S_{11}=\frac{Z_{\text {in }}-50}{Z_{\text {in }}+50}, S_{21}=2 \frac{V_{\mathrm{y}}}{E_{\mathrm{s}}}=2 \frac{V_{\mathrm{y}}}{V_{\mathrm{b}}} \frac{V_{\mathrm{b}}}{V_{\mathrm{s}}} \frac{V_{\mathrm{s}}}{E_{\mathrm{s}}} .
$$

$S_{21}$ is obtained indirectly with a well-known approach by applying shifting in the reference planes (10) [30].

$$
\frac{V_{\mathrm{s}}}{E_{\mathrm{s}}}=\frac{Z_{\mathrm{s}}}{Z_{\mathrm{s}}+Z_{\text {in }}}, \frac{V_{\mathrm{y}}}{V_{\mathrm{b}}}=\frac{\left(1+\Gamma_{\mathrm{y}}\right) \mathrm{e}^{-\gamma_{2} l_{2}}}{1+\Gamma_{\mathrm{y}} \mathrm{e}^{-2 \gamma_{2} l_{2}}}, \frac{V_{\mathrm{b}}}{V_{\mathrm{s}}}=\frac{\left(1+\Gamma_{\mathrm{b}}\right) \mathrm{e}^{-\gamma_{1} l_{1}}}{1+\Gamma_{\mathrm{b}} \mathrm{e}^{-2 \gamma_{1} l_{1}}}
$$

Then, the T-matrix for the each single-branch network can be calculated from S-matrix. For this calculation, the conversion equations are used as shown in (11)

$$
\mathbf{T}=\left[\begin{array}{cc}
\frac{1}{S_{21}} & -\frac{S_{22}}{S_{21}} \\
\frac{S_{11}}{S_{21}} & S_{12}-\frac{S_{11} S_{22}}{S_{21}}
\end{array}\right], \mathbf{S}=\left[\begin{array}{cc}
\frac{T_{21}}{T_{11}} & T_{22}-\frac{T_{21} T_{12}}{T_{11}} \\
\frac{1}{T_{11}} & -\frac{T_{12}}{T_{11}}
\end{array}\right]
$$

Total T-matrix for the N-branch network $\left(\mathbf{T}_{N}\right)$ can be calculated as given in (20) where $\mathbf{T}_{i N}$ represents the T-matrix of the $i^{\text {th }}$ single-branch network. Then, the T-matrix of the whole network can be converted to S-matrix using the (12). The $S_{21}$ term of the S-matrix gives the transfer function of the whole PLC network, $H(f)$.

$$
\mathbf{T}_{N}=\prod_{i=1}^{N}\left[\mathbf{T}_{i N}\right]
$$

For a specific channel bandwidth and a certain channel capacity, the communication link performance can be calculated as a function of energy per bit to noise density ratio $E_{\mathrm{b}} / N_{0}$ as given in (13)

$$
\frac{E_{\mathrm{b}}}{N_{0}}=\frac{C}{N} \frac{B_{\mathrm{w}}}{f_{\mathrm{b}}}
$$

where $C$ is the received signal power (W), $N$ is the total noise power (W), $B_{\mathrm{w}}$ is the channel bandwidth $(\mathrm{Hz})$, and $f_{\mathrm{b}}$ is channel data rate (bit/s) or capacity. In this study, the communication link performance of the busbar PLC system for different network configurations was investigated at CENELEC band $\left(B_{\mathrm{w}}=145.5 \mathrm{kHz}\right.$ between $3 \mathrm{kHz}-$ $148.5 \mathrm{kHz}$ ). In Europe, CENELEC has formed the standard EN-50 065-1, in which the frequency bands, signaling levels and procedures are specified [37]. The transmitted signaling level $\left(V_{\mathrm{t}}\right)$ is limited to $134 \mathrm{~dB} \mu \mathrm{V}$ for industrial areas according to the standard [37] and this value is used for the calculations. Transmitted signal power $S_{\mathrm{t}}(\mathrm{W})$ according to the well-known maximum power transfer theorem and received signal power $C(\mathrm{~W})$ was calculated using (14) where $Z_{\text {in }}$ is input impedance of the network and $H(f)$ is channel transfer function. $Z_{\text {in }}$ is a frequency dependent value. Thus, the mean value of $Z_{\text {in }}$ was utilized for the calculations

$$
S_{\mathrm{t}}=\frac{V_{\mathrm{t}}^{2}}{4 Z_{\text {in }}}, \quad C=S_{\mathrm{t}}|H(f)|^{2} .
$$

Channel transfer function shows also a frequency-dependent characteristic and the attenuation increases with increasing frequency. In (14), the maximum attenuation value of $H(f)$ at this frequency band (worst case) for each network configuration was used for calculations. Finally, the $E_{\mathrm{b}} / N_{0}$ values were calculated with these assumptions for a certain data rate. BER performance analysis vs. SNR of the busbar systems for different network configurations was made for FSK and PSK modulations. Theoretical bit error probabilities $\left(P_{\mathrm{e}}\right)$ for coherent FSK and PSK are given in (15)

$$
P_{\mathrm{e}}^{(\mathrm{FSK})}=\frac{1}{2} \operatorname{erfc} \sqrt{\frac{E_{\mathrm{b}}}{2 N_{0}}}, \quad P_{\mathrm{e}}^{(\mathrm{PSK})}=\frac{1}{2} \operatorname{erfc} \sqrt{\frac{E_{\mathrm{b}}}{N_{0}}}
$$

where $\operatorname{erfc}(*)$ is the complementary error function.

\section{Numerical Results}

To show the effect of the different network topologies on BER performances, some simulations were conducted for $630 \mathrm{~A}, 1250 \mathrm{~A}$, and $2000 \mathrm{~A}$ current level busbars at CENELEC band. Instead of giving results for all signal paths, the worst and best cases in terms of channel attenuation were selected according to the transfer functions as given in Fig. 12.

Thus, L2-L1 signal path for the 630 A current level busbar was determined as the worst case scenario due to maximum attenuation behavior while L3-N signal path for the 2000 A current level busbar was the best case. Then, the achievable channel capacities were determined for the best and worst busbar network topology cases using the Shannon's Theorem as shown in Fig. 13. It shows a rough variation range of channel capacity (Mbps) against PSD of transmitted signal power $(\mathrm{dBm} / \mathrm{Hz})$. For an average PSD of transmitted power $-60 \mathrm{dBm} / \mathrm{Hz}$, the mean of achievable channel capacity is approximately $f_{\mathrm{b}}=1 \mathrm{Mbps}$ from Fig. 13.

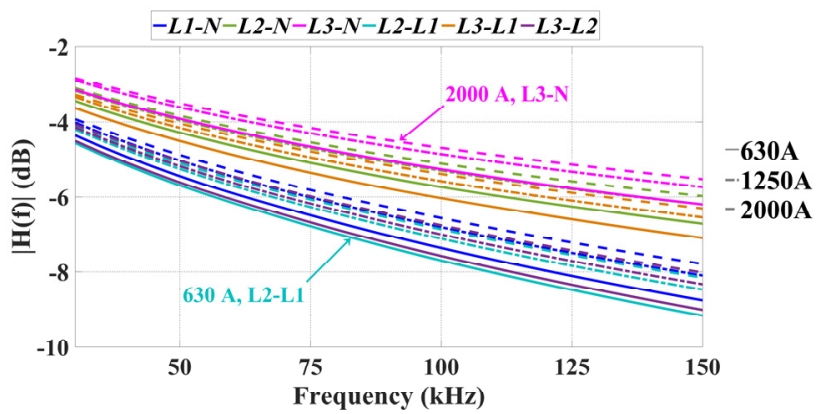

Fig. 12. Transfer functions for all signal paths of a length $100 \mathrm{~m}$ without branch. 


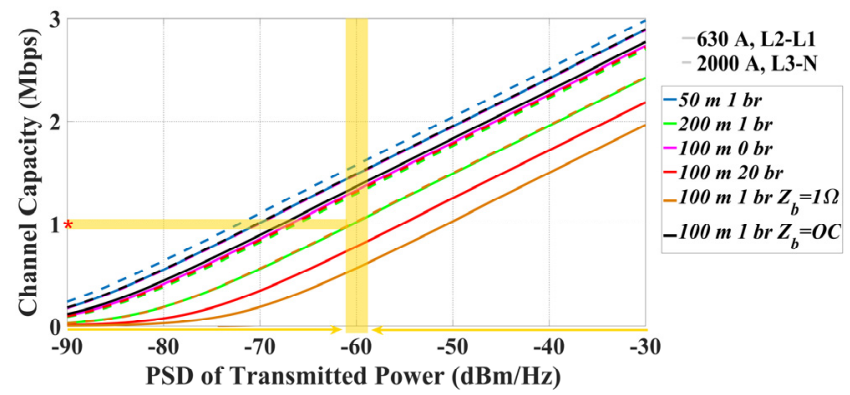

Fig. 13. Channel capacities for different busbar network topologies.

To support the $1 \mathrm{Mbps}$ value, [38] can be referred for typical narrowband channel capacities. For these calculations, load impedances and branch lengths were taken $100 \Omega$ and $3 \mathrm{~m}$, respectively.

Since the largest voltage drop permitted in the LV distribution system is about 3\%, the maximum line length $\left(l_{\mathrm{T}}\right)$ between $T x$ and $R x$ for a 630 A current level busbar can be calculated with provided technical characteristics [23] [18] for $\cos \varphi=0.8$, and $\alpha_{\mathrm{y}}=0.5$ as approximately $150 \mathrm{~m}$ with a well-known formula as shown in (16)

$$
\Delta V=\alpha_{\mathrm{y}} \sqrt{3}\left[l_{\mathrm{T}} I(R \cos \varphi+X \sin \varphi) 10^{-3}\right]
$$

where $\cos \varphi$ is power factor of the line; $\alpha$ is the distribution factor of the loads (or the utilization factor), which depends on the type and number of loads; $l_{\mathrm{T}}$ is the line length (m); $I$ is the line current (A); $R$ is the line resistance $(\mathrm{m} \Omega / \mathrm{m})$; and $X$ is the line reactance $(\mathrm{m} \Omega / \mathrm{m})$. At the same conditions, the maximum $l_{\mathrm{T}}$ will be approximately 195 and $205 \mathrm{~m}$ for $1250 \mathrm{~A}$ and $2000 \mathrm{~A}$ busbars, respectively. For this reason, in the simulation studies, a line length of $200 \mathrm{~m}$ was taken as the maximum length between $T x$ and $R x$.

BER performances vs. SNR are shown in Fig. 14, Fig. 15, and Fig. 16. These figures illustrate the relationship between bit error probability and busbar type, busbar length between $T x$ and $R x$ ( $l_{\mathrm{T}}$ in $\left.\mathrm{m}\right)$, branch number $(b r)$, branch length $\left(l_{\mathrm{b}}\right.$ in $\left.\mathrm{m}\right)$, and branch terminating load $\left(Z_{\mathrm{b}}\right)$ at CENELEC band. The branch terminating load refers to the load impedance at the end of the branch. These results can give an idea for busbar PLC channel especially for remote control applications such as automatic meter reading and remote control systems design.

The BER vs. SNR of a single-branch busbar system for best case and worst case conditions to show the effect of busbar line length are shown in Fig. 14. The $l_{\mathrm{T}}$ was taken as $50,100,150$, and $200 \mathrm{~m}$, branch length was set as $3 \mathrm{~m}$ and terminated with $Z_{\mathrm{b}}=100 \Omega$. The branch was located at the midpoint of $T x-R x$.

In Fig. 15, the BER performances are shown for different branch numbers. The branch number between $T x$ and $R x$ was increased from 0 to 5,10 and 20 for $l_{\mathrm{T}}=100 \mathrm{~m}$. They also were positioned at equal intervals along the $l_{\mathrm{T}}$. Branches were terminated with $Z_{\mathrm{b}}=100 \Omega$, and their lengths were taken $l_{\mathrm{b}}=3 \mathrm{~m}$.

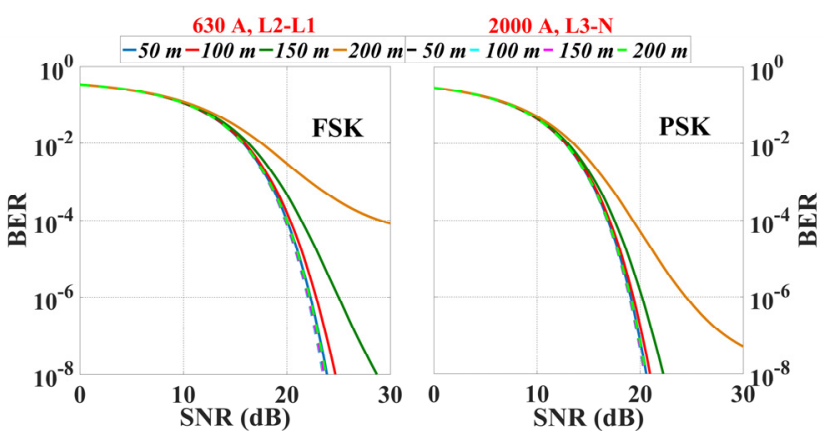

Fig. 14. FSK-PSK bit error probabilities of different busbars for different line lengths between $T x$ and $R x$.

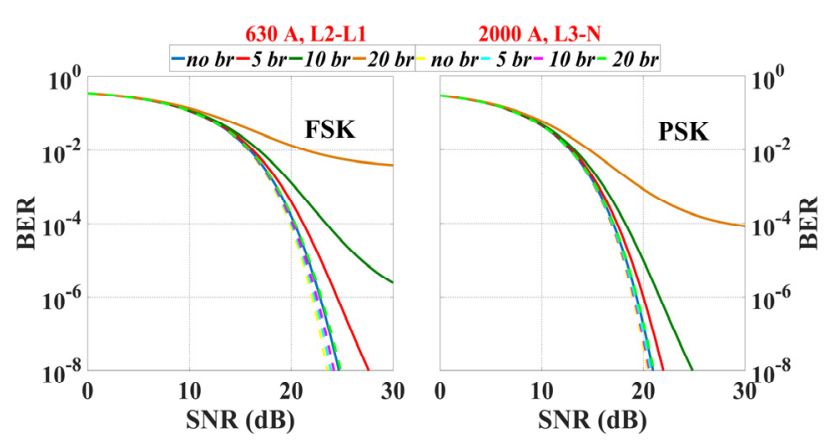

Fig. 15. FSK-PSK bit error probabilities of different busbars for different branch numbers between $T x$ and $R x$.
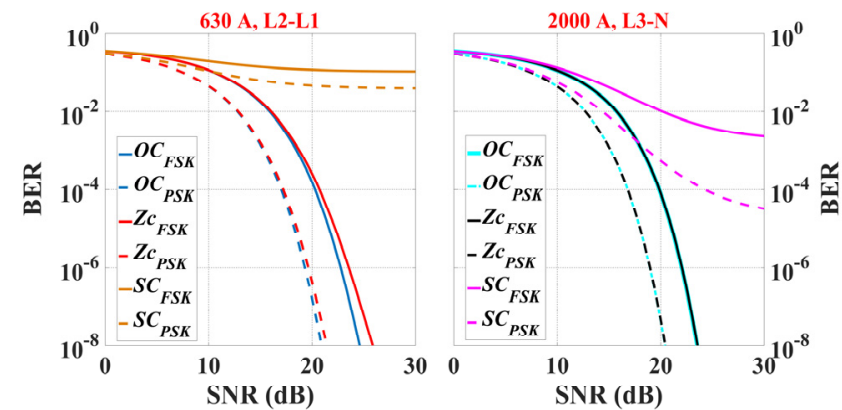

Fig. 16. FSK-PSK bit error probabilities of different busbars for different terminating load impedances.

The load impedance effect on the BER performance of a single-branch busbar was examined for varying $Z_{\mathrm{b}}$ as short circuit $(S C)$, characteristic impedance, and open circuit $(O C)$ as shown in Fig. 16. These examinations were made for $l_{\mathrm{T}}=100 \mathrm{~m}$ and $l_{\mathrm{b}}=3 \mathrm{~m}$ and the branch was located at the midpoint of $T x-R x$.

The effect of branch length, on the other hand, was also investigated and concluded that there are no significant changes over BER performances. Thus, they were not included in this paper.

Obtained findings are very important in solving the communication link design and performance analysis of the narrowband PLC channel for busbar distribution systems. The results of this study can be summarized as follows:

- Different current level busbars (630 A, 1250 A, and 2000 A) were examined for six different signal paths (L1-N, L2-N, L3-N, L2-L1, L3-L1, L3-L2). A fre- 
quency-dependent RLGC(f) model was used to represent the busbar transmission line and model parameters were extracted from measured S-parameters with PSO. The results are given in Figs. 3-8 with 0.93 and 0.98 averaged R-square values for amplitude and phase of $S_{21}$, respectively.

- A bottom-up frequency-domain channel modeling approach was preferred to obtain N-branch busbar distribution network and chain-scattering matrix method was used to determine the whole busbar PLC network. For this aim, a GUI was created to simulate the different busbar network topologies by varying busbar type, signal path, line length, branch number, and load impedances.

- 630 A, L2-L1 was determined as the worst case scenario due to maximum attenuation behavior of $H(f)$ while 2000 A, L3-N was the best channel (Fig. 12).

- The possible line length $\left(l_{\mathrm{T}}\right)$ is limited according to the permitted voltage drop (3\%) at LV grid. Calculated $l_{\mathrm{T}}$ values for $630 \mathrm{~A}, 1250 \mathrm{~A}$ and $2000 \mathrm{~A}$ current level busbars are 150, 195 and $205 \mathrm{~m}$, respectively using (16). In this study, maximum line length was selected as $200 \mathrm{~m}$.

- For the studied network topologies in terms of different busbar line lengths, different branch numbers and different load impedances, $Z_{\text {in }}$ and attenuation (Atten.) ranges can be given in Tab. 3 . These values show the used $Z_{\text {in }}$ and Atten. ranges for the calculations.

- Capacity (data rate) was calculated according to Shannon's Theorem. Bandwidth $\left(B_{\mathrm{w}}\right)$ was taken $145.5 \mathrm{kHz}$ (all CENELEC band). It means that the calculated capacity is the total capacity of the communication link. Capacity varies from $300 \mathrm{kbps}$ to $3 \mathrm{Mbps}$ for the different network topologies as shown in Fig. 13. For an average PSD of transmitted power, the capacity was taken $f_{\mathrm{b}}=1 \mathrm{Mbps}$ for calculations.

- BER vs. SNR performances were obtained for the basic modulations, FSK and PSK. In these calculations, $V_{\mathrm{t}}$ and averaged PSD of background noise (from Fig. 9) were taken $134 \mathrm{~dB} \mu \mathrm{V}$ and $-96 \mathrm{dBV}^{2} / \mathrm{Hz}$, respectively.

- Figs. 14-16 show the BER vs. SNR performances for different channel conditions at both modulation types: FSK and PSK. $200 \mathrm{~m}$ line length has the worst performance (Fig. 14). Additionally, increasing branch number decreases BER performance (Fig. 15). Another important disruptive effect may be defined as load impedance. When the terminating load impedance at the branches decreases, the BER performance of the system decreases (Fig. 16).

As a result, if the line length, branch number, and the terminating load impedances are assumed within a meaningful range, the system performance is an acceptable level for a busbar PLC link. Obtained results from Figs. 14-16 conclude that the BER is smaller than $10^{-5}$ for a $20 \mathrm{~dB}$ SNR value.

\begin{tabular}{|c|c|c|c|c|c|c|}
\hline & \multicolumn{6}{|c|}{ Different network topologies } \\
\hline & \multicolumn{2}{|c|}{$\begin{array}{c}\text { Line Length } \\
\mathbf{5 0} \mathrm{m}<\boldsymbol{l}_{\mathrm{T}}<\mathbf{2 0 0 \mathrm { m }}\end{array}$} & \multicolumn{2}{|c|}{$\begin{array}{c}\text { Branch Number } \\
\mathbf{0}<\boldsymbol{b} r<\mathbf{2 0}\end{array}$} & \multicolumn{2}{|c|}{$\begin{array}{c}\text { Load Impedanc } \\
\mathrm{SC}<\boldsymbol{Z}_{\mathrm{b}}<\text { OC }\end{array}$} \\
\hline & $\begin{array}{l}Z_{\text {in }} \\
(\Omega)\end{array}$ & $\begin{array}{l}\text { Atten. } \\
\text { (dB) }\end{array}$ & $\begin{array}{l}Z_{\text {in }} \\
(\Omega)\end{array}$ & $\begin{array}{l}\text { Atten. } \\
\text { (dB) }\end{array}$ & $\begin{array}{l}Z_{\text {in }} \\
(\Omega)\end{array}$ & $\begin{array}{l}\text { Atten. } \\
\text { (dB) }\end{array}$ \\
\hline $630 \mathrm{~A}, \mathrm{~L} 2-\mathrm{L} 1$ & $25-30$ & $4.5-18$ & $27-33.5$ & $8.8-20$ & $12.5-29.5$ & $8.2-31$ \\
\hline $2000 \mathrm{~A}, \mathrm{~L} 3-\mathrm{N}$ & $6.5-14.5$ & $2.7-10.5$ & $9.6-30$ & $5-8.8$ & $2-10.3$ & $5-26.3$ \\
\hline
\end{tabular}

Tab. 3. The observed $Z_{\text {in }}$ and Atten. ranges for studied different network configurations.

\section{Conclusion}

Busbar is a key element of modern distribution systems in LV grid especially in industrial areas to carry high power. As one of the main targets of the smart grid is to increase the energy quality, existing grid undoubtedly needs some information and communication technologies (ICT). PLC is one of the most powerful communication technique in the smart grid concept. Thus, busbar should be examined in terms of PLC possibilities to provide an integrated communication network in the LV grid. On the other hand, M2M is one of the important backbones in the smart grid. Because busbar is generally used in the industrial areas, it provides a natural link between machines. If PLC over busbar is succeeded, no extra cabling and RF link are needed for an integrated M2M communication. Thus, it is essential to know the characteristics of the busbar distribution systems for providing PLC communication to contribute to the existing literature.

While cable models have been proposed for narrowband PLC applications, no modeling of busbars as transmission lines have been offered in terms of PLC and the smart-grid concept to the best of the authors' knowledge. The results gained from this study show that discussed busbar PLC system can be realized and applied in existing power grids. On the other hand, the worst-case BER performances can be improved using advanced modulation, coding and error correction techniques. As a result, PLC system designers will be aware of the busbar's characteristics and possible link performances with the help of this study.

\section{Acknowledgments}

This work was supported by the TUBITAK (The Scientific and Technological Research Council of Turkey), 1003- Primary Subjects R\&D Funding Program, Project No: EEEAG-115E137. The authors would like to thank also EAE Company for their support providing the busbar distribution systems.

\section{References}

[1] PAPAZYAN, R. PETTERSON, P., EDIN, H., ERIKSSON, R., GAFVERT, U. Extraction of high frequency power cable 
characteristics from S-parameter measurements. IEEE Transactions on Dielectrics and Insulation, 2004, vol. 11, no. 3, p. 461-470. DOI: 10.1109/TDEI.2004.1306724

[2] HASIRCI, Z., CAVDAR, I. H. Modeling of high power busbar systems for power line communications. In IEEE International Energy Conference (ENERGYCON 2014). Dubrovnik (Croatia), 2014, p. 1515-1519. DOI: 10.1109/ENERGYCON.2014.6850623

[3] HASIRCI, Z., CAVDAR, I. H., SULJANOVIC, N., MUJCIC, A. Investigation of current variation effect on PLC channel characteristics of LV high power busbar systems. In The 5th IEEE PES European 2014 Conference on Innovative Smart Grid Technologies (ISGT). Istanbul (Turkey), 2014, 5 p. DOI 10.1109/ISGTEurope.2014.7028778

[4] MARKS, R. B., WILlIAMS, D. F. Characteristic impedance determination using propagation constant measurement. IEEE Microwave Guided Wave Letters, 1991, vol. 1, no. 6, p. 141-143. DOI: $10.1109 / 75.9109210 .1109 / 75.91092$

[5] GOldberG, S. B., STEER, M. B., FRAnZON, P. D. Experimental electrical characterization of interconnects and discontinuities in high-speed digital systems. IEEE Transactions on Components, Hybrids, and Manufacturing Technology, 1991, vol. 14, no. 4, p. 761-765. DOI: 10.1109/33.105130

[6] WILliams, D. F., ROGERS, J. E., HOLLOWAY, C. L. Multiconductor transmission - line characterization: Representations, approximations, and accuracy. IEEE Transactions on Microwave Theory and Techniques, 1999, vol. 47, no. 4, p. 403-409. DOI: $10.1109 / 22.754872$

[7] CHEN, G., ZHU, L., MELDE, K. Extraction of frequency dependent RLCG parameters of the packaging interconnects on low-loss substrates from frequency domain measurements. In 14th Topical Meeting on Electrical Performance of Electronic Packaging (IEEE-EPEP 2005). 2005, p. 25-28. DOI: 10.1109/EPEP.2005.1563691

[8] KIM, J., HAN, D. Hybrid method for frequency-dependent lossy coupled transmission line characterization and modeling. In Electrical Performance of Electronic Packaging (EPEP2003). Princeton (NJ, USA), 2003, p. 239-242. DOI: 10.1109/EPEP.2003.1250040

[9] DEUTSCH, A., ARJAVAlingaM, G., KOPCSAY, G. V. Characterization of resistive transmission lines by short-pulse propagation. IEEE Microwave and Guided Wave Letters, 1992 (current ver. 2002), vol. 2, no. 1, p. 25-27. DOI: $10.1109 / 75.109132$

[10] FERRARI, P., FLECHET, B., ANGENIEUX, G. Time domain characterization of lossy arbitrary characteristic impedance transmission lines. IEEE Microwave and Guided Wave Letters, 1994 (current ver. 2002), vol. 4, no. 6, p. 177-179. DOI: $10.1109 / 75.294284$

[11] KIM, W., LEE, S., SEO, M., SWAMINATHAN, M., TUMMALA, R. Determination of propagation constants of transmission lines using 1-Port TDR measurements. In 59th ARFTG Conference Digest. Seattle (WA, USA), 2002, p. 119-126. DOI: 10.1109/ARFTGS.2002.1214689

[12] Degerstrom, M. J., GILBERT, B. K., DANIEL, E. S. Accurate resistance, inductance, capacitance, and conductance (RLCG) from uniform transmission line measurements. In Electrical Performance of Electronic Packaging (IEEEEPEP2008). San Jose (CA, USA), 2008, p. 77-80. DOI: 10.1109/EPEP.2008.4675881

[13] ZUNIGA-JUAREZ, J. E., REYNOSO-HERNANDEZ, J. A., MAYA-SANCHEZ, M. C., MURPHY-ARTEAGA, R. S. A new analytical method to calculate the characteristic impedance $\mathrm{Zc}$ of uniform transmission line. Computación y Sistemas, 2012, vol. 16, no. 3 , p. $277-285$.
[14] REYNOSO-HERNANDEZ, J. A. Unified method for determining the complex propagation constant of reflecting and nonreflecting transmission lines. IEEE Microwave and Wireless Components Letters, 2003, vol. 13, no. 8, p. 351-353. DOI: 10.1109/LMWC.2003.815695

[15] BIANCO, B., PARODI, R. M. Determination of the propagation constant of uniform microstrip lines. Alta Frequence, 1976, vol. 45 , no. 2 , p.107-110.

[16] JANEZIC, M. D., JARGON, J. A. Complex permittivity determination from propagation constant measurements. IEEE Microwave and Guided Wave Letters, 1999, vol. 9, no. 2, p. 76-78. DOI: $10.1109 / 75.755052$

[17] REYNOSO-HERNÁNDEZ, J. A., ESTRADA-MALDONADO, C. F., PARRA, T., GRENIER, K., GRAFFEUIL, J. An improved method for the wave propagation constant estimation in broadband uniform millimeter-wave transmission line. Microwave and Optical Technology Letters, 1999, vol. 22, no. 4, p. 268-271. DOI: 10.1002/(SICI)1098-2760(19990820)22:4<268::AIDMOP16>3.0.CO;2-6

[18] ZHANG, J., CHEN, Q. B., QIU, Z., DREWNIAK, J. L., ORLANDI, A. Extraction of causal RLGC models from measurements for signal link path analysis. In 2008 International Symposium on Electromagnetic Compatibility - EMC Europe. Hamburg (Germany), 2008, 6 p. ISSN: 2325-0356. DOI: 10.1109/EMCEUROPE.2008.4786839

[19] ZHANG, J., DREWNIAK, J. L., POMMERENKE, D. J., KOLEDINTSEVA, M. Y., DUBROFF, R. E., CHENG, W., YANG, Z., CHEN, Q. B., ORLANDI, A. Causal RLGC(f) models for transmission lines from measured S-parameters. IEEE Transactions on Electromagnetic Compatibility, 2010, vol. 52, no. 1, p. 189-198. DOI: 10.1109/TEMC.2009.2035055

[20] ZHANG, J., KOLEDINTSEVA, M. Y., DREWNIAK, J. L., ANTONINI, G., ORLANDI, A. Extracting R, L, G, C parameters of dispersive planar transmission lines from measured $\mathrm{S}$ parameters using a genetic algorithm. In International Symposium on Electromagnetic Compatibility, EMC 2004. Eindhoven (Netherlands), 2004, vol. $2, \quad$ p. $572-576 . \quad$ DOI: 10.1109/ISEMC.2004.1349861

[21] HASIRCI, Z., CAVDAR, I. H. Extraction of narrowband propagation properties of a $630 \mathrm{~A}$ current level busbar. In 39th International Conference on Telecommunications and Signal Processing, TSP 2016. Vienna (Austria), 2016, p. 203-206. DOI: 10.1109/TSP.2016.7760860

[22] HASIRCI, Z., CAVDAR, I. H., OZTURK, M. Estimation of propagation parameters for aluminum busbar up to $500 \mathrm{kHz}$. In 2016 International Symposium on Innovations in Intelligent Systems and Applications (INISTA). Sinaia (Romania), 2016. DOI: 10.1109/INISTA.2016.7571824

[23] EAE COMPANY, TURKEY. E-Line KX Busbar Power Distribution System (datasheet). 57 pages. [Online] Cited 2016-05-03. Available at: http://eae.com.tr/EAE-ENG/upload/ELine\%20KX_eng.pdf

[24] GUPTA, K. C., GARG, R., CHADHA, R. Computer Aided Design of Microwave Circuits. Dedham (MA): Artech House, p. 2543, 1981. ISBN: 9780890061053

[25] BAKHOUM, E. G. S-parameters model for data communications over 3-phase transmission lines. IEEE Transactions on Smart Grid, 2011, vol. 2, no. 4, p. 615-623. DOI: 10.1109/TSG.2011.2168613

[26] SAMPATH, M. K. On addressing the practical issues in the extraction of RLGC parameters for lossy multi-conductor transmission lines using S-parameter models. In Electrical Performance of Electronic Packaging (IEEE-EPEP2008). San Jose (CA, USA), 2008, p. 259-262. DOI: 10.1109/EPEP.2008.4675929 
[27] MARKS, R. B. A multiline method of network analyzer calibration. IEEE Transactions on Microwave Theory and Technique, 1991 (current ver. 2002), vol. 39, no. 7, p. 1205-1215. DOI: $10.1109 / 22.85388$

[28] KIM, J., HAN, D. H. Hybrid method for frequency-dependent lossy coupled transmission line characterization and modelling. In 12th Topical Meeting on Electrical Performance of Electronic Packaging (IEEE-EPEP 2003). Princeton (NJ, USA), 2003, p. 239-242. DOI: 10.1109/EPEP.2003.1250040

[29] KENNEDY, J., EBERHART, R. C. Particle swarm optimization. In Proceedings of IEEE International Conference on Neural Networks. Piscataway (NJ), 1995, p. 1942-1948. DOI: 10.1109/ICNN.1995.488968

[30] POZAR, D. M. Microwave Engineering. $4^{\text {th }}$ ed. New York (USA): Wiley, 2012. ISBN: 9780470631553

[31] Goodness-of-Fit Statistics. [Online] Cited 2016-08-30. Available at:http://web.maths.unsw.edu.au/ adelle/Garvan/Assays/Goodness OfFit.html

[32] CORTES, J. A., DIEZ, L., CANETE, F. J., SANCHEZMARTINEZ, J. J. Analysis of the indoor broadband power-line noise scenario. IEEE Transactions on Electromagnetic Compatibility, 2010, vol. 52, no. 4, p. 849-858. DOI: 10.1109/TEMC.2010.2052463

[33] KATAYAMA, M., YAMAZATO, T., OKADA, H. A. Mathematical model of noise in narrowband power line communication systems. IEEE Journal on Selected Areas in Communications, 2006, vol. 24, no. 7, p. 1267-1276. DOI: 10.1109/JSAC.2006.874408

[34] LIU, W. Emulation of Narrowband Powerline Data Transmission Channels and Evaluation of PLC Systems. Ph.D. dissertation, p. 163-166 Elektrotechnik und Informationstechnik, Karlsruher Institut für Technologie, Karlsruhe, Germany, 2013. ISBN:978-37315-0071-1

[35] MENG, H., CHEN, S., GUAN, Y. L., LAW, C. L., SO, P. L., GUNAWAN, E., LIE, T. T. Modeling of transfer characteristics for the broadband power line communication channel. IEEE Transactions on Power Delivery, 2004, vol. 19, no. 3, p. 1057-1064. DOI: 10.1109/TPWRD.2004.824430

[36] GONZALEZ, G. Microwave Transistor Amplifiers. $2^{\text {nd }}$ ed. Englewood Cliffs (NJ): Prentice-Hall, 1997. ISBN: 9780132543354
[37] Standard on Low-Voltage Electrical Installations in the Frequency Range $3 \mathrm{kHz}$ to $148.5 \mathrm{kHz}$, Part One, CENELEC Std. EN500651:19 917A1:1992, 1992.

[38] TONELlO, A. M., PITTOLO, A. Considerations on narrowband and broadband power line communication for smart grids. In IEEE International Conference on Smart Grid Communications (SmartGridComm). Miami (FL, USA), 2015. DOI: 10.1109/SmartGridComm.2015.7436269

\section{About the Authors ...}

Zeynep HASIRCI was born in Samsun, Turkey. She received B.Sc. and M.Sc. degrees from Karadeniz Technical University (KTU) in 2008 and 2011, respectively. She studied for her Ph.D. thesis in Halmstad University, Sweden for one year. She is currently a Ph.D. student at the Dept. of Electrical and Electronics Engineering, KTU. Her research interests include communication systems, mobile and satellite communication, propagation modeling and power line communication.

Ismail Hakki CAVDAR was born in Trabzon, Turkey. He received his Ph.D. degree in Electrical and Electronics Engineering from Karadeniz Technical University (KTU), in 1994. He has been a Full Professor at KTU since 1985. He was a Visiting Professor at Smart Grid Lab in the Dept. of Electrical and Computer Engineering, The University of Akron, OH USA, in 2011. His research interests include communications systems, mobile and satellite communication, power line communications, smart grids and power electronics.

Mehmet OZTURK was born in Trabzon, Turkey. He received his B.Sc degree in Electronics Engineering from Kadir Has University in 2004. He received his M. Sc. and $\mathrm{Ph} . \mathrm{D}$. degrees in Electrical and Electronics Engineering from Karadeniz Technical University (KTU) in 2007 and 2013, respectively. His research interests include biomedical, signal and image processing, point clouds. 